HrLL, L. R. (1959). J. gen. Microbiol. 20, 277-283

\title{
The Adansonian Classification of the Staphylococci
}

\author{
By L. R. HILL \\ Public Health Laboratory, Royal Infirmary, Cardiff
}

SUMMARY: The Adansonian method of classification, in which all features are given equal weight in deducing similarity between strains, has been applied to staphylococci. Staphylococcus aureus, S. saprophyticus and $S$. roseus are natural groups, but $\boldsymbol{S}$. lactis and $\boldsymbol{S}$. afermentans are not, for individual strains of these 'species' are as different from each other as from the three previous species. The group as a whole is divided into two main branches which might be regarded conveniently as two genera, Staphylococcus and Micrococcus.

A new approach to bacterial systematics was proposed by Sneath $(1957 a, b)$ in which taxonomic features were handled mathematically to calculate similarity $(S)$ values between strains. Strains were then sorted into groups of like $S$ values. This system is different from classical taxonomy, not so much in its novel mechanics, as in a shift away from the view that some features of an organism are more important than others for classification purposes. Systematic bacteriology appears to be more an art than a science, the art of choosing important features. We know from experience with higher organisms that features which are conveniently regarded as important are essentially correlated features. In the 'Adansonian' approach to taxonomy, advocated by Sneath, bias in choosing important features is eliminated by giving all features equal weight initially. A wide range of features is taken, a percentage similarity between strains calculated, and groups are deduced impartially. Correlated features should then arise as the result of classification and not as a pre-requisite to it. Sneath's original papers should be consulted for the theoretical and practical aspects of this method of taxonomy.

The staphylococcus-micrococcus group of organisms has always been an enigma to bacterial systematists. The working classification of the National Collection of Type Cultures (NCTC), proposed by Shaw, Stitt \& Cowan (1951), consists of five species only. In Bergey's Manual (1957) there are forty-three species in the family Micrococcaceae. The group has led to at least one unorthodox classification by Abd-el-Malek \& Gibson (1948), who regarded it as forming a linear series, at one end of which were the pathogenic staphylococci and, at the other end, a thermoduric saprophyte (red micrococci were omitted). Although they believed that the series was essentially continuous, 'nodal points' (Wilson, 1955) were distinguishable at which numerous strains were grouped together. These could have been given Linnaean-like names, though in fact this was not done.

It was thought that $(a)$ the Adansonian method might provide, at last, a good classification for the group, and $(b)$ that staphylococci should form a rigorous proving-ground for a method of taxonomy which seems to have great possibilities. 


\section{METHODS}

Strains were collected from nasal swabs of healthy persons, purulent lesions, animal carcasses, milk, air, the NCTC, and the collection of the Botany Department of the University College, Cardiff. They were described in terms of eighty features which are listed in Table 1.

Table 1. List of features used as differential characters in this study

\begin{tabular}{lcll}
\multicolumn{1}{c}{ Test } & $\begin{array}{c}\text { No. of } \\
\text { features }\end{array}$ & \multicolumn{1}{c}{ Test } & $\begin{array}{c}\text { No. of } \\
\text { feature }\end{array}$ \\
Gram reaction & $\mathbf{2}$ & Fermentation of & \\
Diameter of cells & $\mathbf{4}$ & Glucose & $\mathbf{1}$ \\
Cell arrangements & $\mathbf{6}$ & D(t)-xylose & $\mathbf{1}$ \\
Colonial morphology & $\mathbf{3}$ & Lactose & $\mathbf{1}$ \\
Degree of golden pigmentation & $\mathbf{3}$ & Sucrose & $\mathbf{1}$ \\
Pink, yellow and white pigments & $\mathbf{1}$ & Maltose & $\mathbf{1}$ \\
& each & Mannitol & $\mathbf{1}$ \\
Optimal temperature & $\mathbf{2}$ & Salicin & $\mathbf{1}$ \\
Growth in nutrient broth & $\mathbf{2}$ & Voges-Proskauer & $\mathbf{1}$ \\
Pellicle & 1 & Methyl red & $\mathbf{1}$ \\
Degree of anaerobic growth & $\mathbf{2}$ & Urease & $\mathbf{2}$ \\
Catalase & $\mathbf{1}$ & Degree of gelatin liquefaction & $\mathbf{2}$ \\
Bound coagulase & $\mathbf{2}$ & Nitrate reduction & $\mathbf{1}$ \\
Free coagulase & $\mathbf{3}$ & Methylene blue reduction & $\mathbf{2}$ \\
$\alpha$-Haemolysin & $\mathbf{3}$ & NH salt utilization & $\mathbf{2}$ \\
$\beta$-, $\delta$-, $\epsilon$-Haemolysins & $\mathbf{1}$ & Caseinase & $\mathbf{2}$ \\
& each & Degree of serum digestion & $\mathbf{2}$ \\
Lipase & $\mathbf{1}$ & NaCl tolerance & $\mathbf{3}$ \\
Phosphatase & 1 & Heat sensitivity & $\mathbf{3}$ \\
Fibrinolysin & $\mathbf{2}$ & Phenol sensitivity & $\mathbf{4}$ \\
Floceulation lines & $\mathbf{2}$ & & \\
Penicillinase & $\mathbf{2}$ & &
\end{tabular}

\section{Morphology}

Two degrees of Gram-positiveness were recognized, dependent upon the ease of decolorization. Three groups were delineated by measuring cell diameters, 0.6-0.8, 0.9-1.0 and $1 \cdot 1-1 \cdot 3 \mu$. Cell arrangements recognized were 'bunches of grapes', loose-lying, tetrads, cubes of eight, chains of more than five cells, and the presence of pleomorphic cells (individual cells considerably larger than the majority in the smear).

Cultures grown on nutrient agar at $37^{\circ}$ for $48 \mathrm{hr}$. were characterized as minute streptococcal-like colonies, typical staphylococcal colonies either 'Rough' or 'Smooth', and having tackiness determined with a wire loop.

From cultures grown on $30 \%$ milk agar at $37^{\circ}$ for $48 \mathrm{hr}$. followed by 3 days on the bench, pigments recognized were golden yellow $(1+, 2+$ or $3+)$, pink, lemon-yellow, and white.

\section{Physiology}

Nutrient agar cultures were grown at $22^{\circ}, 30^{\circ}$ and $37^{\circ}$ to determine optimal growth temperature. Growth in nutrient broth (after $24 \mathrm{hr}$. at $37^{\circ}$ ) was described as uniform turbidity with compact deposit, or slight turbidity with granular diffuse deposit. Surface ring pellicles were also noted. 
Growth under anaerobic conditions (McIntosh and Fildes's jar) was described as profuse or reduced.

Loopfuls of test organisms were emulsified into drops of $20 \mathrm{vol} . \mathrm{H}_{2} \mathrm{O}_{2}$ on a slide and recorded as catalase positive when bubbles were evolved.

'Bound' coagulase (slide test, Duthie, 1954) was described as causing rapid or slow clumping, and 'free' coagulase (tube test) divided into $1+, 2+$ or $\mathbf{3}+$ categories according to titre.

Elek \& Levy's (1950 b) nomenclature for the haemolysins was followed as their technique was used. The $\alpha$-haemolysin was described as $1+, 2+$ or $3+$ according to the measured width of the zone of lysis, and also recognized were the $\beta-, \delta$ - and $\epsilon$-haemolysins.

Lipase was detected on Marks's (1952) tributyrin agar and phosphatase by phenolphthalein phosphate agar (Barber \& Kuper, 1951).

Fibrinolysin $(1+$ or $2+)$ was detected with precipitated fibrin agar plates (Lack, 1957).

Flocculation lines produced against staphylococcal antitoxin paper strips (Elek \& Levy, 1950 a) were also divided into $1+$ and $2+(1-4$ lines, and more than four lines produced, respectively).

Strains were divided into $1+$ and $2+$ producers of penicillinase by using the method of Parker \& Lapage (1957) in which the Oxford staphylococcus was used as a standard.

\section{Biochemistry}

Nutrient agars incorporating various carbohydrates and bromcresol purple indicator were used for identifying fermentation reactions. (This method is probably less sensitive than a tube method, but it serves most efficiently to separate two main groups ultimately found.)

Voges-Proskauer (Barritt's modification) and methyl red reactions were carried out as described by Mackie \& McCartney (1953).

Urease was detected on Christensen's urea agar slants incubated at $37^{\circ}$ and described as $\mathbf{1}+$ or $\mathbf{2}+$.

Nutrient gelatin stab cultures were incubated at $22^{\circ}$ for up to 30 days and liquefaction was also described as $1+$ or $2+$.

Sulphanilic acid and $\alpha$-naphthylamine reagents were used in the nitrate reduction to nitrite test on 5-day cultures grown in nitrate broth at $37^{\circ}$.

Decolorization of methylene blue added to nutrient broth cultures was described as partial or complete.

Hucker's (Bergey's Manual, 6th ed., 1948) medium was used to detect ammonium salt utilization and results were recorded as growth only, or growth with acid production.

$20 \%(\mathrm{v} / \mathrm{v})$ milk agar gave clear indication of casein hydrolysis.

Serum digestion on Loeffler's slopes incubated at $37^{\circ}$ was described as $1+$ or $2+$.

Sodium chloride tolerance was determined with 9,12 and $15 \%(w / v)$ $\mathrm{NaCl}$ nutrient agars; heat and phenol sensitivities by the methods of Sneath (1956). 
Both the method of deriving Adansonian classifications and the systems of scoring quantitative data are described by Sneath (1957b).

\section{RESULTS}

The organisms were provisionally classified according to the scheme of Shaw et al. (1951). They comprised: 20 strains of Staphylococcus aureus; 8 strains of $S$. saprophyticus; 9 strains of $S$. lactis; 7 strains of $S$. roseus; 5 strains of S. afermentans.

An $i \times m$ (strains $\times$ features) table was drawn up, $\% S$ values for each pair of strains were calculated, and an $i \times i$ (strains $\times$ strains) table was prepared. Groups were sorted from these $\% S$ values and intra- and inter-group mean square $S$ values further calculated from a rearranged $i \times i$ table (which is represented in Fig. 1). A taxonomic tree was then designed and is presented here as Fig. 2. Two main branches were found which may tentatively be regarded as two genera.

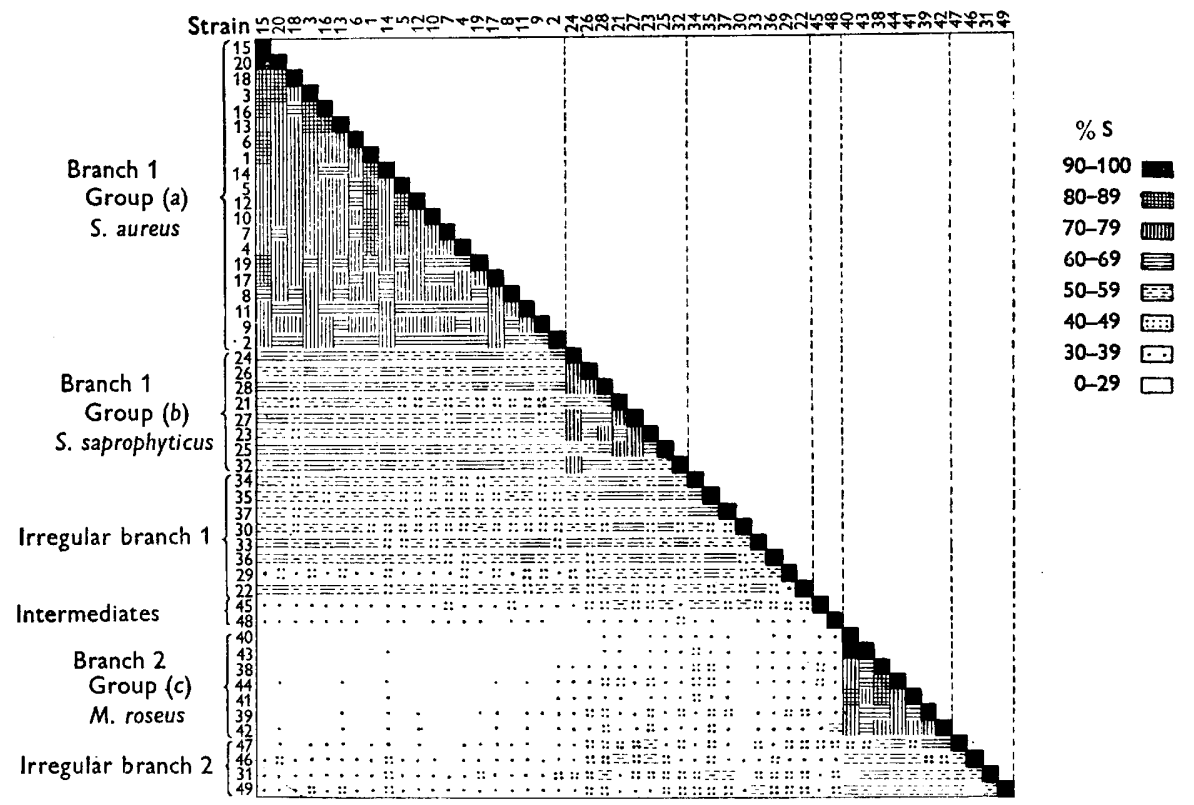

Fig. 1. Diagrammatic representation of the full $\% S$ value table.

Three of the groups defined by the Shaw et al. scheme remained as groups when subjected to Adansonian analysis. These were (a) Staphylococcus aureus, (b) $S$. saprophyticus, and $(c) S$. roseus. However, from the diagram it can be seen that groups $(a)$ and $(b)$ join together at a higher $\% S$ level than they do with group $(c)$, indicating that $S$. aureus and $S$. saprophyticus are more closely related than they are to $S$. roseus. Also, single strains joined independently on to one or other of the two main branches, all at much the same $\% S$ level. Two strains were intermediate between the two main branches. 


$\% s \mathbf{1 0} \quad 20 \quad 30 \quad 40 \quad 50 \quad 60 \quad 70 \quad 80 \quad 90 \quad 100 \% s$

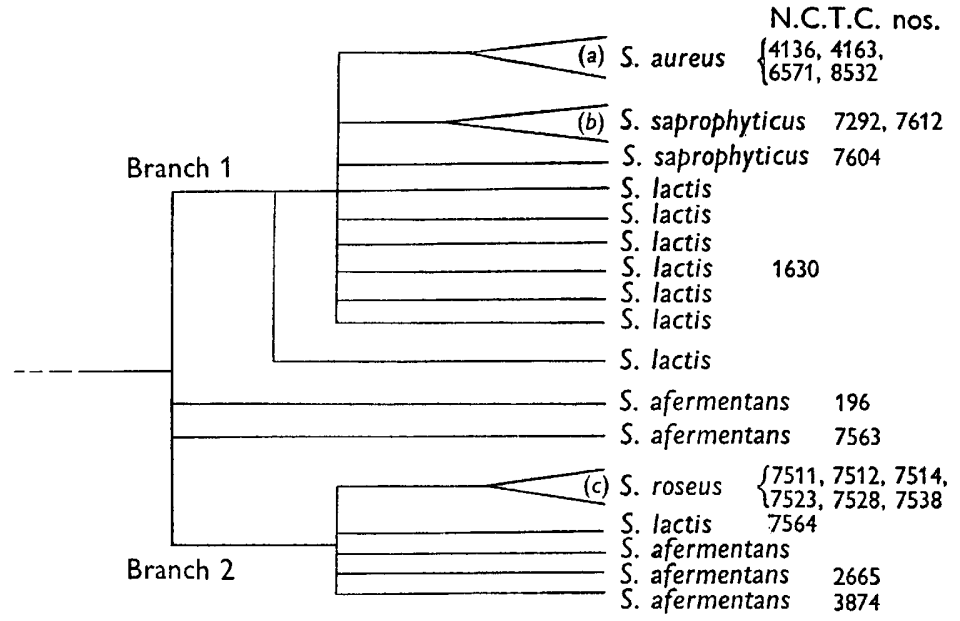

Fig. 2. Taxonomic tree of the group according to Adansonian analysis. (Names are those according to the Shaw et al. 1951 scheme.)

\section{DISCUSSION}

The three species Staphylococcus aureus, S. saprophyticus and S. roseus are natural groups and can be accepted as logical classification. The possession of the same generic name, however, implies that these three species are equally closely related to one another. The Adansonian classification, on the other hand, clearly indicates that $S$. aureus and $S$. saprophyticus are much more closely related to each other than they are to $S$. roseus. A truer reflexion of the relationships of these three species would be shown if the name Staphylococcus roseus was changed to Micrococcus roseus. The generic term Staphylococcus could then be reserved for branch 1 in the Adansonian classification, comprising strains typically from human or animal sources and capable of fermenting a wide range of sugars (by the plate technique). Micrococcus could be used for strains of branch 2, which are not typically parasitic and which are generally inactive biochemically, especially in lacking fermentative powers (by the same technique).

If branches 1 and 2 of the Adansonian classification are to be regarded as two genera, Staphylococcus is undoubtedly the correct name for branch 1, as $S$. aureus is a name conserved by the Judicial Commission on Bacteriological Nomenclature (1958), with strain NCTC 8532 (no. 4 in this paper) as neotype. The correct name for group (b), called here $S$. saprophyticus, is in doubt for the group corresponds to $S$. epidermidis (Winslow \& Winslow) Evans in Bergey's Manual (1957).

The name Micrococcus for branch 2 is also of doubtful legality for the Judicial Commission (1958) has not yet considered the validity of the name Micrococcus luteus. However, the name $\boldsymbol{M}$. roseus Flügge is widely used and would be convenient for group $(c)$ in the Adansonian classification, with 
strain NCTC 7523 (type strain for Staphylococcus roseus Tavel proposed by Shaw et al.) as neotype.

It seems premature to recognize Staphylococcus lactis and $S$. afermentans as species, for the Adansonian classification shows them to be artificial groups. This is not an unexpected result, because both species were defined by Shaw et al. (1951) mainly upon negative features. The essential features given for $S$. lactis were coagulase-negative, acid from glucose, Voges-Proskauer negative and the absence of pink pigment. There were only two essential features for $S$. afermentans, coagulase-negative and acid not produced from glucose. That this is not sound taxonomy is shown up in the Adansonian classification in which each strain of these 'species' constitutes a separate group, equal in status to the three previously named species. Unless one is particularly interested in one of these strains their nomenclature could be limited to simply 'miscellaneous staphylococci (fermentative)' or 'miscellaneous micrococci (non-fermentative).' Strains 45 and 48 are properly called intermediate, whilst strain 29 is one of the miscellaneous staphylococci rather more irregular than the majority.

An identification key can be drawn up for recognizing five groups only as shown below:

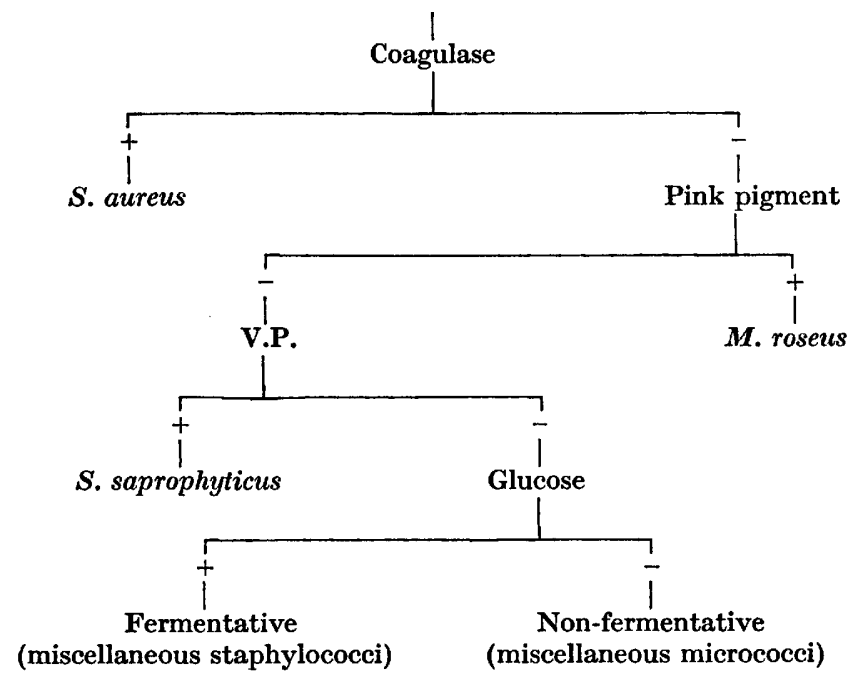

The characters chosen are those which are most constant in these groups. If a strain should happen to be aberrant in one of these characters it would be misclassified if this key were used alone, but it should be possible to identify such strains if they are checked with the characters given in Table 2. Thus, if a typical strain of the Staphylococcus aureus, S. saprophyticus or Micrococcus roseus is encountered it can be readily recognized on a few tests only. If a strain does not fit into any of these groups, even after checking with Table 2, then it can be described as simply fermentative or non-fermentative (plate technique). This indicates to which genus the strain probably belongs, but only a full investigation of its properties will reveal its true taxonomic position. 
Table 2. General properties of the three recognizable species

\begin{tabular}{llcc}
\multicolumn{1}{c}{ Property } & S. aureus & S. saprophyticus & M. roseus \\
Golden yellow & Usually + & Usually - & - \\
White & Usually & Usually + & - \\
Pink & - & - & + \\
Free coagulase & + & - & - \\
$\alpha$-lysin & Usually + & - & - \\
Phosphatase & + & Often + & - \\
V.P., M.R. & Usually+ & Usually + & - \\
Mannitol & Usually+ & Often + & -
\end{tabular}

I wish to thank Professor Scott Thomson for laboratory accommodation and for encouragement throughout the investigation, Dr P. H. A. Sneath for his interest and help in preparing this paper, Dr S. T. Cowan for advice on the scope of the work, and all those who assisted by sending me cultures. This study was carried out during the tenure of a Research Fellowship provided by the Welsh Regional Hospital Board and administered by the Medical Research Council.

\section{REFERENCES}

Abd-el-Malek, Y. \& Grbson, T. (1948). Studies in the bacteriology of milk. II. The staphylococci and micrococci of milk. J. Dairy Res. 15, 249.

BARBER, M. \& KUPER, S. W. A. (1951). Identification of Staphylococcus pyogenes by the phosphatase reaction. J. Path. Bact. 63, 65 .

Bergey's Manual of Determinative Bacteriology (1948). 6th ed. Ed. by Breed, R. S., Murray, E. G. D. \& Hitchens, A.P.,p. 235. London: Baillière, Tindall and Cox.

Bergey's Manual of Determinative Bacteriology (1957). 7th ed. Ed. by BreEd, R. S., Murray, E. G. D. \& Smith, N. R., p. 454. London: Baillière, Tindall and Cox.

DuthIE, E. S. (1954) Evidence of two forms of staphylococcal coagulase. J. gen. Microbiol. 10, 427.

ELeK, S. D. \& Levy, E. (1950a). Diffusible antigens in staphylococcal cultures. Brit. J. exp. Path. 31, 358.

ELEK, S. D. \& LEVY, E. (1950b). Distribution of haemolysins in pathogenic and non-pathogenic staphylococci. J. Path. Bact. 62, 541.

Judicial Commission on Bacteriological Nomenclature (1958). Int. Bull. bact. Nomen. \& Taxon. (in the Press).

LACK, C. H. (1957). Plate coagulase and fibrinolysin tests for staphylococci. $J$. clin. Path. 10, 208.

Mackie, T. J. \& McCartney, J. E. (1953). Handbook of Practical Bacteriology, 9th ed. p. 428. Edinburgh: E. and S. Livingstone Ltd.

MARKS, J. (1952). Recognition of pathogenic staphylococci, with notes on nonspecific staphylococcal haemolysins. J. Path. Bact. 64, 175.

Parker, M. T. \& Lapage, S. P. (1957). Penicillinase production by Staphylococcus aureus strains from outbreaks of food-poisoning. J. clin. Path. 10, 313.

Shaw, C., StitT, J. M. \& Cowan, S. T. (1951). Staphylococci and their classification. J. gen. Microbiol. 5, 1010.

SNEATH, P. H. A. (1956). Cultural and biochemical characters of the genus Chromobacterium. J. gen. Microbiol. 15, 70.

SNEATH, P. H. A. (1957a). Some thoughts on bacterial classification. J. gen. Microbiol. $17,184$.

SNeAth, P. H. A. (1957b). The application of computers to taxonomy. J. gen. Microbiol. 17, 201.

Wirson, G. S. (1955). Symposium discussion on the Principles of Microbial Classification. J. gen. Microbiol. 12, 321.

(Received 16 October 1958) 